\title{
Position Resolution Studies with MSU 32-fold Segmented HPGe Detector
}

C. E. Lehner, K. Vetter, A. Kuhn, G. J. Schmid, D. A. Beckedahl, J. J. Blair, J. E. Kammeraad, T. Glasmacher

Lawrence Livermore National Laboratory
This article was submitted to Institute of Electrical and Electronics Engineers Nuclear Science Symposium, San Diego, CA, November 5-10, 2001

\section{October 25, 2001}




\section{DISCLAIMER}

This document was prepared as an account of work sponsored by an agency of the United States Government. Neither the United States Government nor the University of California nor any of their employees, makes any warranty, express or implied, or assumes any legal liability or responsibility for the accuracy, completeness, or usefulness of any information, apparatus, product, or process disclosed, or represents that its use would not infringe privately owned rights. Reference herein to any specific commercial product, process, or service by trade name, trademark, manufacturer, or otherwise, does not necessarily constitute or imply its endorsement, recommendation, or favoring by the United States Government or the University of California. The views and opinions of authors expressed herein do not necessarily state or reflect those of the United States Government or the University of California, and shall not be used for advertising or product endorsement purposes.

This is a preprint of a paper intended for publication in a journal or proceedings. Since changes may be made before publication, this preprint is made available with the understanding that it will not be cited or reproduced without the permission of the author.

This work was performed under the auspices of the United States Department of Energy by the University of California, Lawrence Livermore National Laboratory under contract No. W-7405-Eng-48.

This report has been reproduced directly from the best available copy.

Available electronically at http://www.doc.gov/bridge

Available for a processing fee to U.S. Department of Energy

And its contractors in paper from

U.S. Department of Energy

Office of Scientific and Technical Information

P.O. Box 62

Oak Ridge, TN 37831-0062

Telephone: (865) 576-8401

Facsimile: (865) 576-5728

E-mail: reports@adonis.osti.gov

Available for the sale to the public from

U.S. Department of Commerce

National Technical Information Service

5285 Port Royal Road

Springfield, VA 22161

Telephone: (800) 553-6847

Facsimile: (703) 605-6900

E-mail: orders@ntis.fedworld.gov

Online ordering: http://www.ntis.gov/ordering.htm

Or

Lawrence Livermore National Laboratory

Technical Information Department's Digital Library

http://www.llnl.gov/tid/Library.html 


\title{
Position resolution studies with MSU 32-fold segmented HPGe detector
}

\author{
C.E. Lehner, K. Vetter, A. Kuhn, G.J. Schmid, D.A. Beckedahl, J.J. Blair, J.E. Kammeraad, T. \\ Glasmacher
}

\begin{abstract}
We present position sensitivity measurements obtained with one of the 32-fold segmented HPGe detectors from Michigan State University. These measurements were performed with a collimated beam of ${ }^{137} \mathrm{Cs}$ gamma rays scattered by 90 degrees. This deposits $374 \mathrm{keV}$ at a given location inside the crystal. A position resulution can be determined over many events by examining the digitally recorded pulse shapes on the 32 electrical contacts. If position resolution is adequate, gamma ray Compton camera imaging may be possible.
\end{abstract}

\section{INTRODUCTION}

F OR the last several years, we have been studying position resolution in commercial segmented high-purity germanium (HPGe) gamma ray detector systems [1],[2]. Segmented detectors have applications in both nuclear physics experiments and in gamma ray imaging using Compton methods. We discuss here the program to measure position resolution in one of the 32-fold segmented HPGe detectors from MSU, shown in Fig. 1 with the preamplifier covers removed. This detector, manufactured by Eurysis in Cedex, France, was designed for in-beam gamma ray spectroscopy at the National Superconducting Cyclotron Laboratory at MSU. The segmentation scheme allows for a position-dependent Doppler correction to be applied, yielding better energy resolution and cleaner gamma ray spectra.

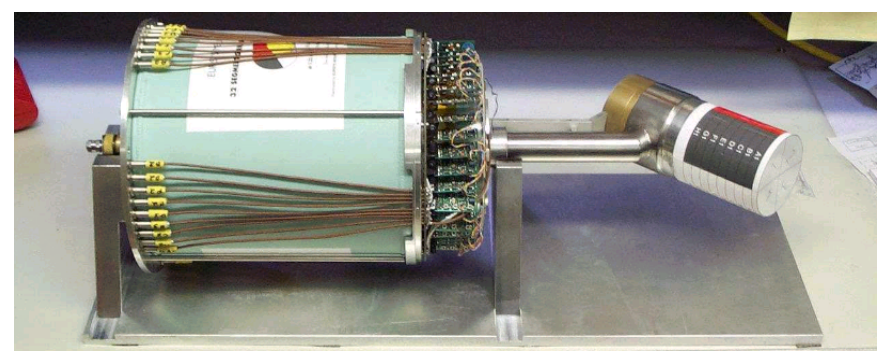

Fig. 1. The MSU detector. The preamplifier covers have been removed. The canister is set at a 45 degree angle to the dewar to allow close packing of several detectors without dewar interference.

As we have shown in our previous work, position resolution can be much smaller than segment size if digital pulse shape analysis is used. We discuss here the best 3-D position resolution achievable in the MSU detector and how that resolution varies with location in the crystal. With good position resolution, it may be possible to determine the location of the first gamma ray interaction in the detector, further improving the Doppler correction for in-beam experiments. Additionally, Compton imaging could be performed if position resolution is sufficiently small.
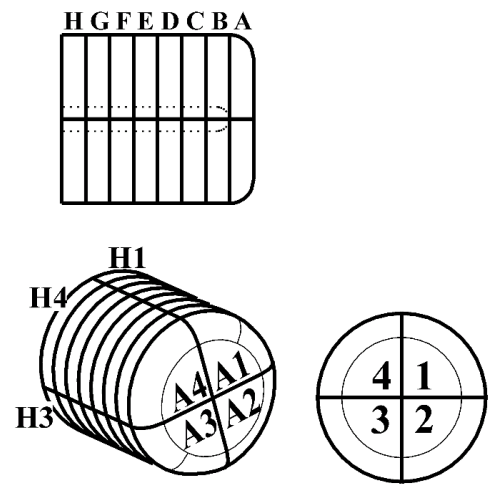

Fig. 2. Segmentation scheme of the MSU detector. There are eight longitudinal and four angular sections for a total of 32 segments.

This research was performed at the UC LLNL and LBNL under the auspices of the US DOE under contract W-7405-Eng-48, and under appointment to the US DOE Nuclear Engineering and Health Physics Fellowship Program sponsored by the DOE Office of Nuclear Energy, Science, and Technology. 


\section{MSU SEgMENTEd Detector}

The MSU detector is a closed-ended coaxial n-type HPGe detector. It is $80 \mathrm{~mm}$ in length, $70 \mathrm{~mm}$ in diameter, and has a bevelled front edge. The segmentation scheme is shown in Fig. 2. The outer contact is segmented into 8 longitudinal and 4 angular sections for a total of 32 segments.

The FETs are warm during operation. The can is angled 45 degrees from the dewar, so that several of these detectors can be placed in close proximity without interference from the dewars. In beam experiments, the side of the detector, not the closed ended front, face the incident radiation.

\section{Calculated Signals}

Using digital techniques, position resolution can be calculated from knowledge of pulse shapes from each segment. We present first the calculations, and in the next section the measured signals.

To calculate the expected pulse shapes from the collecting and noncollecting electrodes we apply Ramo's theorem [3] for weighting potentials. It is necessary to determine the electric field throughout the detector under operating conditions, as well as the weighted potentials for each segment. Maxwell 3D was used to simulate the electric field in the detector, assuming a nominal space charge of $0.002 \mathrm{C} / \mathrm{m}^{3}$, corresponding to an impurity density of about $10^{10} \mathrm{~cm}^{-3}$. The exact distribution of space charge in the crystal is not known, and the value above is assumed to be constant throughout. The electric field through the center slice of the $\mathrm{C}$ segments is plotted in Fig. 3.

The weighting potentials were then calculated by setting the potential of one segment to $1 \mathrm{~V}$ and all other contacts to $0 \mathrm{~V}$. The space charge was excluded in the calculations. The weighting potential through the center slice of the $\mathrm{C}$ segments is shown in Fig. 4.

We calculated expected signals from the electric field and weighting potentials as in [1]. Further, these signals were convolved with the measured preamplifier responses. A square wave with $5 \mathrm{~ns}$ rise time and 4 ?s period was sent into the test input of the detector, and the corresponding output signals were read from the segments. The preamplifier repsonses were determined by deconvolving the input and output signals without filtering.

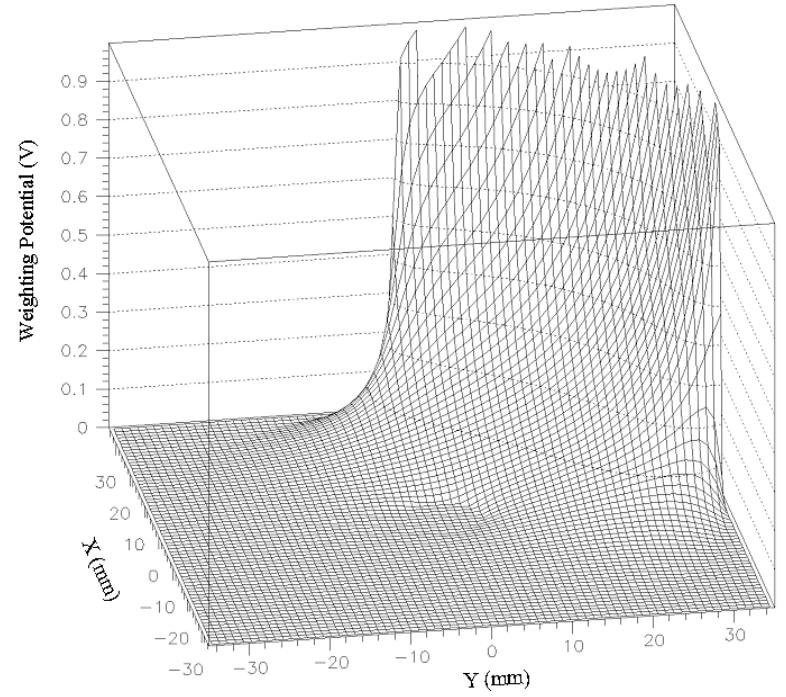

Fig. 4. Simulated weighting potential in the center slice $(z=25)$ of segment $C 2$., calculated by setting $C 2$ to $1 \mathrm{~V}$ and all other contacts to $0 \mathrm{~V}$. Granularity is due to the finite grid size on which the potential is calculated.

\section{Measured Signals}

To benchmark these calculations it is necessary to measure the signals corresponding to interactions at particular sites and compare the results with calculations. A collimated ${ }^{137} \mathrm{Cs}$ source was placed in front of the detector, determining interaction position in two dimensions. The gamma rays which scattered at approximately 90 degrees were collimated in the third dimension before being absorbed in a NaI detector. The NaI detector was $12.7 \mathrm{~cm}(5 \mathrm{in})$ in diameter and $15.2 \mathrm{~cm}(6 \mathrm{in})$ in length. Coincident events between the HPGe and NaI detectors triggered the digitization of signals. To reduce background coincidences, an energy gate around $374 \mathrm{keV}$ was used on the HPGe signals, implying a 90 degree scatter event. Using the 1 mm collimators and a source activity of $1 \mathrm{mCi}$, we obtain a count rate of about 1 event every 10 minutes if the interaction is near the edge of the crystal, or every 30-60 minutes if the interaction is deeper inside the crystal.

The signals were fed into a fast amplifier and then a waveform digitizer with a sampling rate of $500 \mathrm{MHz}$. The central contact (full energy), NaI coincidence, and coincidence timing signals were also digitized. Data was acquired for segment 
$\mathrm{C} 2$ in 24-hour intervals at $16(\mathrm{x}, \mathrm{y})$ locations for $2(\mathrm{z})$ depths. The first depth is $1 \mathrm{~mm}$ away from the B-C segment boundary, and the second is halfway through $\mathrm{C} 2$. The interaction locations are shown in Fig. 5.

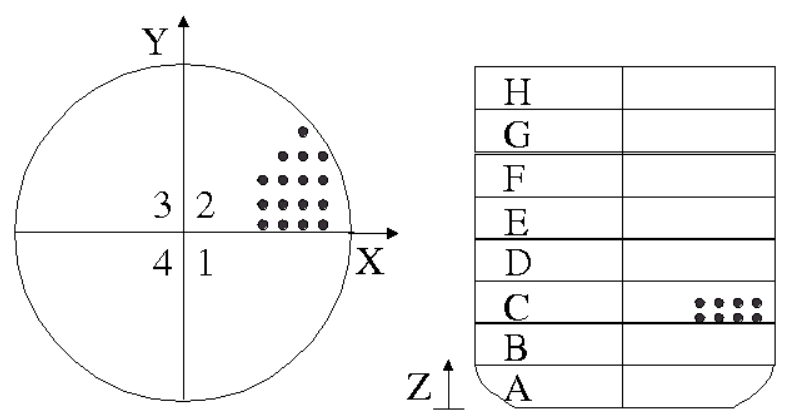

Fig. 5. Locations of interactions for calculated pulse shapes.

Figs. 6 and 7 shows the calculated and measured pulse shapes for two points located $1 \mathrm{~mm}$ from the B2 boundary. The signals in Fig. 6 are from a point near the $\mathrm{C} 1$ boundary, and those in Fig. 7 correspond to a point in the middle of the C2 segment. Shown in Figs. 8 and 9 are the same points at the second depth.

The calculated signals match fairly well with measured signals, with the exception of B2. The calculated transient signals have a larger amplitude than the measured signals at both points near the B segment boundary. This is not observed consistently for the other spectator signals. It cannot be due to errors in alignment, because the reverse effect is not observed in the D segments.

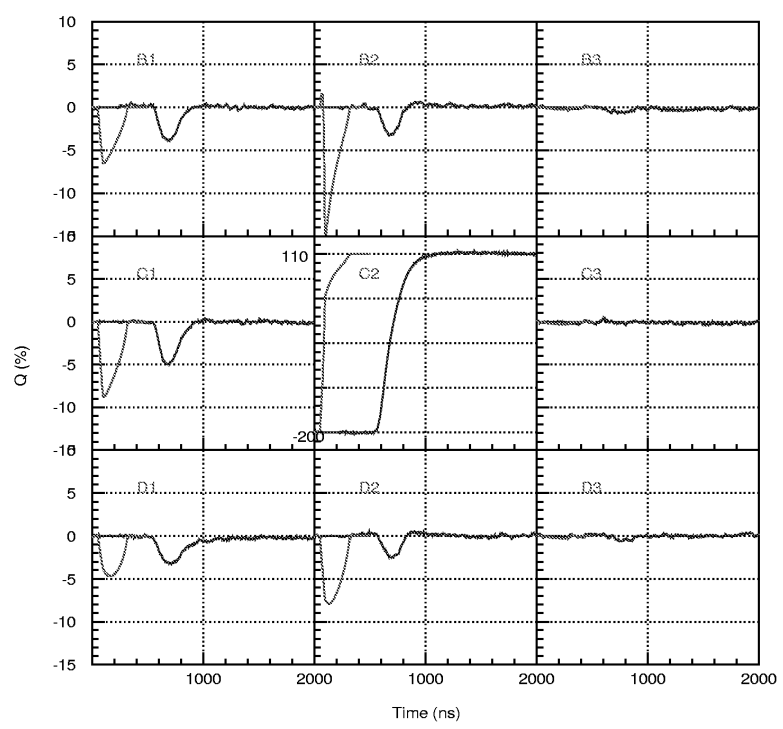

Fig. 6. Measured and calculated pulse shapes in C2 near the C1 boundary at $x=30, y=5, z=21$.

Fig. 7. Measured and calculated signals in the middle of $C 2$ at $x=25, y=20, z=21$. 

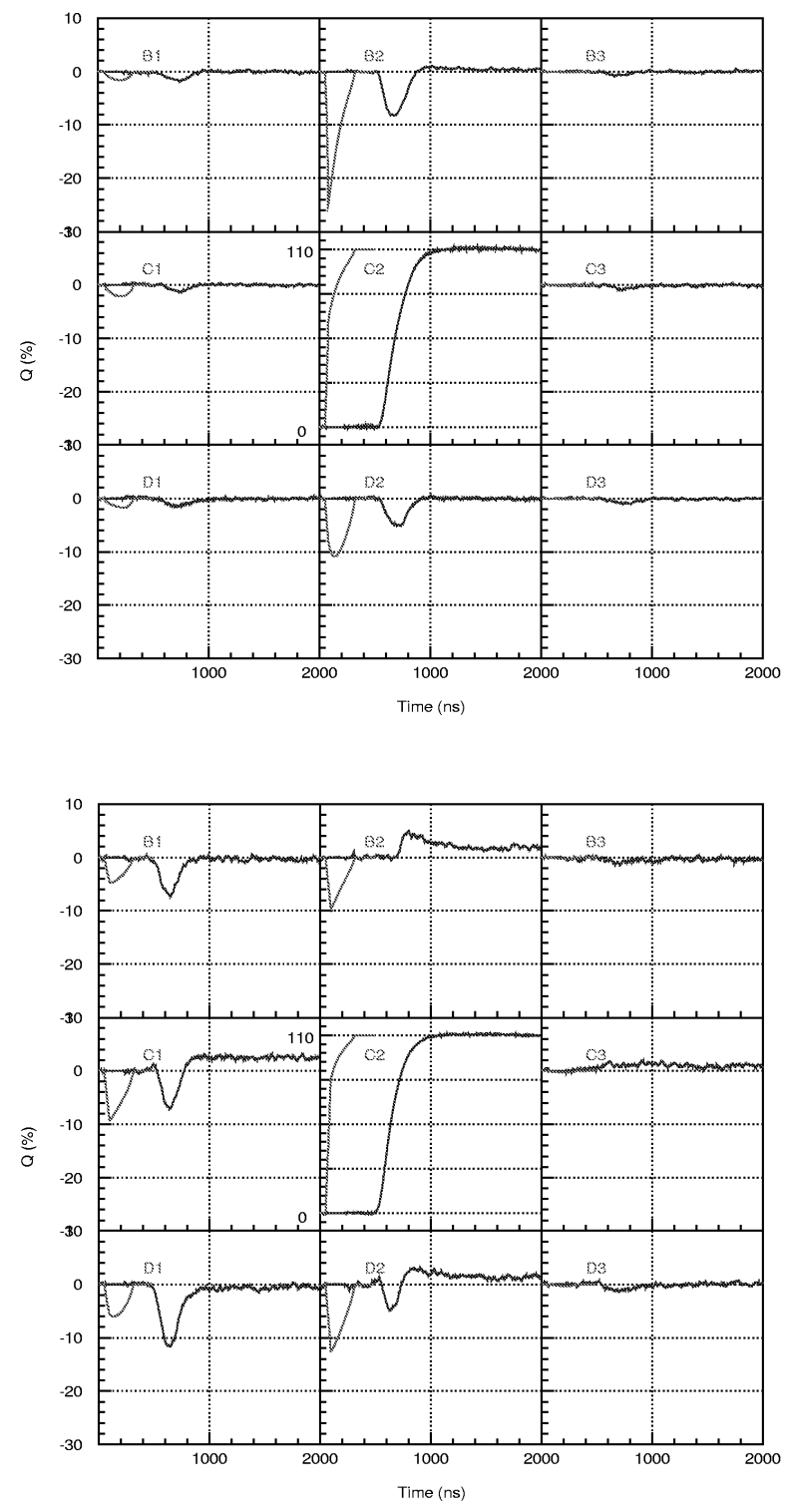

Fig. 8. Same as in Fig. 6 except $z=25$.

However, the expected trends are observed. There is a larger spectator signal on the nearer angular neighboring segments (e.g. the amplitude of D1 is larger than D3). Additionally, in Figs. 6 and 7 the B segments have larger signals than the D segments, as expected for an interaction near the B-C boundary. The amplitude of the $\mathrm{C} 1$ signal does not change with depth of interaction, although the induced signal on D2 is $50 \%$ larger at $(25,21)$ than at $(31,5)$ for both depths.

\section{Position Resolution}

Position sensitivity was calculated as in [1]. The noise level was measured to be about $6 \mathrm{keV}$ for all segments, and this constant value was used in the calculations. The minimum and maximum sensitivities calculated were $\mathrm{X}$ and $\mathrm{Y}$. 


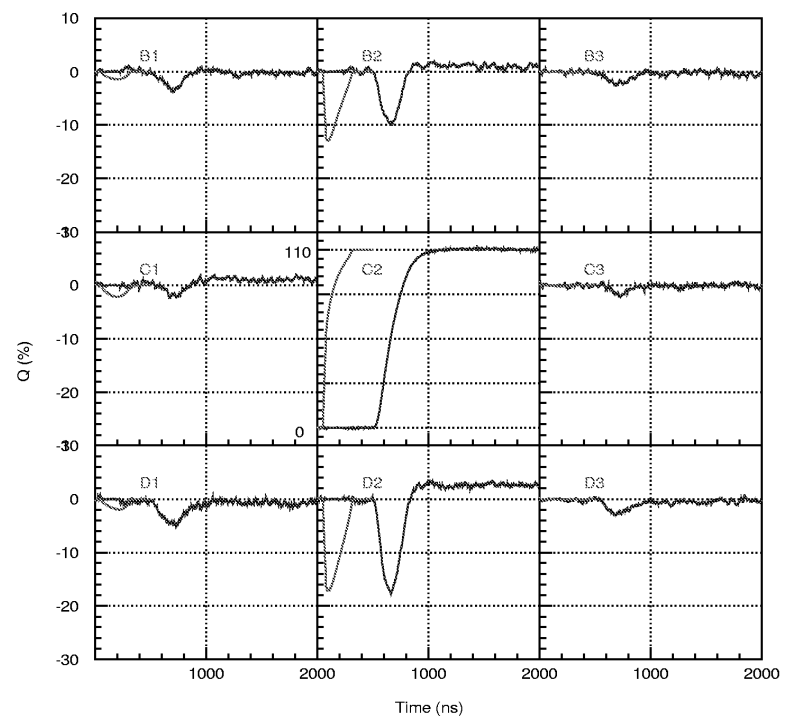

Fig. 9. Same as in Fig. 7 except $z=25$.

\section{Conclusions}

We have performed measurements and calculations to study position resolution in the MSU 32-fold segmented HPGe detector. Calculations reasonably predicted the signals in single-multiplicity events. Position sensitivity was found to be poor, and is not good enough in this detector to perform Compton imaging. To achieve any reasonable image resolution in the reconstruction process, the position resolution in the detector must be much smaller (sub-millimeter if possible).

\section{REFERENCES}

[1] K. Vetter, A. Kuhn, M.A. Deleplanque, I.Y. Lee, F.S. Stephens, G.J. Schmid, et al., "Three-dimensional position sensitivity in two-dimensionally segmented HP-Ge detectors," in Nucl. Instr. Meth. A, vol. 452, pp. 223-238.

[2] G.J. Schmid, D.A. Beckedahl, J.E. Kammeraad, J.J. Blair, K. Vetter, A. Kuhn, "Gamma-ray Compton camera imaging with a segmented HPGe," in Nucl. Instr. Meth. A, vol. 459, pp. 565-576.

[3] S. Ramo, Proc. IRE 27(1939) 584. 